\title{
In defence of governance: ethics review and social research
}

\author{
Mark Sheehan, Michael Dunn, Kate Sahan
}

Nuffield Department of Population Health, The Ethox Centre, University of Oxford, Oxford, UK

\section{Correspondence to} Dr Mark Sheehan, Nuffield Department of Population Health, The Ethox Centre, University of Oxford, Oxford OX3 7LF, UK;

mark.sheehan@philosophy. ox.ac.uk

Received 20 June 2017 Revised 31 July 2017

Accepted 24 September 2017 Published Online First 10 October 2017

\section{Linked}

- http://dx.doi.org/10.1136/ medethics-2018-104975

- http://dx.doi.org/10.1136/ medethics-2017-104668

Check for updates

To cite: Sheehan M, Dunn M, Sahan K. J Med Ethics 2018:44:710-716.

\section{ABSTRACT}

There is a growing body of literature that has sought to undermine systems of ethical regulation, and governance more generally, within the social sciences. In this paper, we argue that any general claim for a system of research ethics governance in social research depends on clarifying the nature of the stake that society has in research. We show that certain accounts of this stakeprotecting researchers' freedoms; ensuring accountability for resources; safeguarding welfare; and supporting democracy — raise relevant ethical considerations that are reasonably contested. However, these accounts cannot underpin a general claim in favour of, or against, a system of research ethics governance. Instead, we defend governance in social research on the grounds that research, as an institutionalised form of enquiry, is a constitutive element of human flourishing, and that society ought to be concerned with the flourishing of its members. We conclude by considering the governance arrangements that follow from, and are justified by, our arguments.

\section{INTRODUCTION}

A growing body of literature has launched severe attacks on systems of ethical regulation, and governance more generally, within the social sciences. These criticisms question the value, need and appropriateness of governance arrangements, some even claiming that ethics review of social research is unethical.

In this paper, we respond to the ethical and practical claims underpinning these challenges. We do not simply debunk these claims in order to justify the ethics governance of social research. Instead, we address two related challenges about the relationship between governance and social research in order to comment on the appropriateness, or not, of particular governance arrangements in the social sciences.

The first challenge is to provide an account of the relationship between research and society that can ground a general claim for a system of research ethics governance across the social sciences. A key requirement of such an account lies in its potential extension to other research ethics review contexts (eg, medical research), broader research governance issues (eg, patient and public involvement), and to non-empirical research in the social sciences and humanities. The second challenge is to justify and derive a form of governance arrangements from this account.

\section{Against research ethics governance}

Research ethics governance requirements for research with human subjects vary by country.
Combined national statements in the USA and Canada require broadly the same of social research as biomedical, behavioural and even engineering research. ${ }^{1-3}$ In contrast, UK social research requirements are stand-alone and are set out by research councils and learnt societies. They apply to all researchers with membership or funding from these organisations. ${ }^{4-6}$ Such requirements also function less formally as best practice guidelines within institutions. Arguments against research ethics governance of social research target its requirements, its 'functions' or bodies that provide research ethics review such as research ethics committees (RECs), and its nature as a system overall.

The Economic and Social Research Council (ESRC) Framework for Research Ethics ${ }^{6}$ is perhaps the paradigmatic example in the UK, and was a key driver for research ethics review of social research within UK universities. ${ }^{7}$ This document requires researchers to uphold ethical principles including informed consent, confidentiality, avoidance of harm and conflict of interest declarations. The research must also meet certain minimum standards of ethical review, approval and monitoring. Failures to uphold principles or requirements are called to account by the ESRC and sanctions applied. These include the immediate suspension of project funding, and a halt to considering further applications from the researcher or their employing institution.

Unsurprisingly, a backlash has followed which mirrors medical researchers' reactions to the formalising of UK research ethics governance in the 1990 s. $^{8}$ In the remainder of this section, we consider a range of claims (ethical and practical) made against research ethics governance.

\section{Ethical claims against research ethics governance}

Three broad kinds of ethical claims are made against research ethics governance: (1) that RECs, as the key component of research governance, rely on an ethical authority that they do not possess, (2) that research ethics governance violates a right to research and (3) that in social research there is a lack of harm rendering regulation unwarranted. We discuss each of these in turn.

The first claim questions the authority of RECs, as suggested by Hammersley's comment that REC authority is 'presumably based on an appeal to expertise'.9 RECs have authority to approve research because of their expertise in ethical decision-making. But the objection questions both the fact of REC expertise and any robust and defensible concept of such expertise. Hammersley's presumption here looks to be flawed when 
examining how RECs actually function. As Dixon-Woods et al suggest:

The authority of RECs' decisions derives not from their appeal to the moral superiority of any ethical position, but through their place in the organisational structure and the social positioning of the parties to the process thus implied. ${ }^{10}$

A more robust concern about REC authority focuses on the normative legitimacy of RECs: what is the justification for a system or process of ethics governance? Answering this question will engage with how processes more generally can be justified (rather than how they come to be taken as justified). ${ }^{11 \mathrm{i}}$ This form of the question cannot be lightly dismissed despite attempts to do so, for example, by branding research ethics governance an indefensible form of 'moralism'? . How to answer this question lies at the heart of the current paper.

The second kind of ethical claim against research ethics governance appeals to a right to conduct research, and takes several forms. Taking regulation as censorship and research as analogous to speech and expression, the right to research involves freedom of speech and expression. ${ }^{11}$ This right is unjustifiably impinged in social research compared with, say, journalism. ${ }^{12}$ On these views research ethics governance infringes freedom of speech. Alternatively, research involves the right to privacy: research is our private business so long as it does not harm others. Finally, we might view researcher autonomy as the right that is threatened by research ethics governance. ${ }^{13}$

The final ethical claim made against research ethics governance involves the overall lack of harm in social research. Although it is legitimate to curtail the right to research because of risk of harm to others, social research is not risky enough to warrant this:

HSS researchers do nothing that begins to compare with injecting someone with potentially toxic green stuff that cannot be neutralised or rapidly eliminated from their body if something goes wrong. ${ }^{11}$

These three claims, and our response to them, are important for our arguments about the relationship between society and social research in the next section.

\section{Practical claims against research ethics governance}

A second category of claims are more practically oriented, but retain their ethical force. An impractical system will generally be unethical: it will be inefficient, ineffective and undermine the benefits of social research.

First, the governance of any research involves costs that affect the justification of governance generally and consideration of its appropriate form. A commonly encountered practical form of governance-the process of research ethics review-incurs process costs: the research time, money and effort involved in, and arguably wasted on, administration and regulatory compliance. ${ }^{14-16}$ Process costs generate a further ethical concern: that the process supplants proper consideration of the ethics. Researchers might concentrate getting through the ethics, or jumping 'hoops' to approval, rather than addressing the

\footnotetext{
${ }^{i}$ Buchanan and Keohane distinguish normative and sociological legitimacy, thus: "Legitimacy" has both a normative and a sociological meaning. To say that an institution is legitimate in the normative sense is to assert that it has the right to rule-where ruling includes promulgating rules and attempting to secure compliance with them by attaching costs to noncompliance and/or benefits to compliance. An institution is legitimate in the sociological sense when it is widely believed to have the right to rule'. ${ }^{42}$ Dingwall ${ }^{11}$ discusses legitimacy in the sociological sense
} but not in the normative sense. reason for the 'hoops'.9 1718 This might breed cynicism among researchers towards the process and negatively affect their appreciation of ethical standards and conduct in research. ${ }^{19}$

Second, significant elements of the medical research ethics governance model have been inappropriately imported into the social sciences given (1) its lack of risk of harm, ${ }^{11}$ (2) its freer approach to consent ${ }^{20-22}$ and (3) its different methodologies. ${ }^{23-25}$ Clearly a system of research ethics governance that is unattuned to social research will be unable to weigh the appropriateness of different forms of consent and assess different kinds of harms and benefits to participants and society.

Our defence is mindful of the force of these practical points in a way that we are not for the ethical claims outlined above. In particular, the imposition of the 'medical model' of research ethics governance runs counter to whatever justification of governance is available. It is important, however, that this 'medical model' objection is to a particular form of governance, and so cannot tell against a general justification for governance.

\section{Society's stake in social research}

Having discussed ethical and practical claims made against research ethics governance in social research, we now focus on the normative arguments for its governance, with research ethics review as one aspect of this. Our strategy here is to account for the relationship between research and society: if we can develop an account of what kind of stake society has in social research, and why it has such a stake, we will be in a position to make a claim about research ethics governance, and to say something about the form that such governance should take. ${ }^{\text {ii }}$

The four most plausible accounts of that stake are rooted in the following societal concerns: (1) the exercise of liberty of social researchers as members of society; (2) the accountability of social research for using society's resources; (3) the welfare, protection from harm and respect of social research participants; and (4) social research as a democratic requirement. Examining these accounts will determine whether one or more of them can ground a general claim for governance. We will conclude that none of them can achieve this grounding, but that they do raise relevant considerations that are reasonably contested, and therefore relevant to research ethics governance.

\section{The libertarian account}

The arguments discussed in the first section take a broadly libertarian position: research is an exercise of individual liberty that ought to be respected and not interfered with unless harming others and their liberty. On this account, the state, as a vehicle of society, should only provide resources to enable freedom of choice to be acted on. Thus, the nature and direction of social research should be left to social researchers and not to any wider group. Social research is a way to exercise freedom in society via free speech or privacy rights. Society and its institutions should only intervene to protect individuals from harm or liberty infringements.

As outlined above, the libertarian account has been used to argue against ethical oversight of research. ${ }^{9}{ }^{11}$ Indeed in the US context, research ethics oversight has been deemed an infringement on the First Amendment of the US Constitution. ${ }^{26}$

\footnotetext{
ii There are a range of possible terms that might be used instead of 'stake', including 'investment', 'complicity' and 'responsibility'. While stake is perhaps rather generic, it does seem to be neutral enough to capture the character of the kind of relationship that we are looking for. Exactly what we mean by the term stake will be fleshed out as our arguments develop.
} 
However the form of the right to research is understood, it is hard to see this right as absolute. Defamation laws provide the obvious example of the limits of freedom of speech. If the right to research is not absolute, when and how to overrule it is the more relevant question. The simple assertion of the right to research, given its existence is uncontroversial, contributes nothing to the debate.

Even if we accept this rights-based argument, we encounter another problem when we apply the argument to a social research example. One value of social research lies in is the ways in which it includes numerous, often unrepresented, voices, rather than simply reporting the voice of the researcher. This representativeness raises important questions about ownership of the research. There is a clear difficulty, for example, with the researcher straightforwardly claiming ownership over the voices or experiences of others. We may question a researcher's right to free expression when applied to research that documents the experiences of others.

\section{Accountability for resources}

On this account, society provides the resources for the research and so is entitled to comment and impose its values on the research. Contrary to the libertarian position, such an account would justify a system of research ethics governance in terms of society's financial or material investment in social research. Research ethics review would be one way of holding researchers to account to this investment.

One obvious objection is the fact that society does not always provide such resources. These resources might come from private donations or from charitable trusts. Second, when society does provide the resources for research, it may be paying for the system that manages the research rather than for particular research projects. Finally, even in cases where society does not provide the resources for research, we may still have residual intuitions about the relationship between science and society that facts about resourcing cannot entirely capture. These intuitions are illustrated by US stem cell research's inability to calm the concerns it generated in society, despite its public funding being withdrawn. ${ }^{27} 28$

\section{Welfare, protection from harm and respect for participants}

In certain respects this account is the most intuitively plausible of the four. It holds that the state has an obligation both to protect society's members and to promote their welfare. Moreover, the state should also be concerned with the way in which participants are treated, through, for example, the process of obtaining informed consent. Accordingly, the state has a supervisory role in research in order to ensure benefit and the avoidance of harm to research participants, and their respectful treatment. These considerations are central to the appropriateness of research ethics governance arrangements for medical research. ${ }^{29}$

As discussed in the first section, one of the main arguments made against the research ethics review of social research is its supposed overall lack of risk of harm. Thus even if welfare considerations do justify research ethics governance, they do not provide a general justification: when the risk of harm falls below a certain level, the welfare argument does not apply.

Although we agree with those who counter this position and suggest risks to social research participants may be underestimated, ${ }^{30-32}$ it is also easy to inflate such risks when considering psychological distress or reputational damage. It is perhaps better to recognise that social research spans a spectrum of harms and benefits, with each project's place on the spectrum individually determined. Given this spectrum, harm considerations alone cannot offer a general justification for research ethics governance. A second reason for caution about this approach is in the 'utilitarianisation' of research-that the sole value of research lies in the extent of pre-emptively specified benefits that are traded against possible harms. Such an approach challenges a value of research for its own sake and should be treated with caution if it reduces that value to simplistic and outcome-based considerations.

Before moving on, however, we emphasise that we are not arguing for dismissal of these considerations as irrelevant to questions about research ethics governance. Governance will weigh as many of these considerations (freedom, accountability, welfare, protection from harm and respect) as are raised by individual research projects. Rather we take issue with their ability to function as accounts and so provide a general grounding for the claim that society has a stake in social research.

\section{Research as a democratic requirement}

On this account, democratic citizenship requires that individuals can enquire about the society in which they live. Research as a specific form of enquiry sits within the appropriate functioning of democratic culture and institutions, rather than flowing from a basic human right connected to exercising freedoms. ${ }^{33}$ Thus, democratic institutions enable free enquiry that both helps citizens to function within society and supports the foundations of democracy itself.

This claim looks persuasive, but only in a democratic society context, and so fails to ground a general claim about the stake that society has in research. Even if all societies were democratic, this politicisation of the relationship between enquiry and social life fails to grasp what is important about it. Research is more fundamental than simply being a product of democratic government.

\section{Enquiry as a constitutive element of human flourishing}

We now turn to a fifth account of the stake that society has in social research. We believe that this account adequately explains and grounds the stake that society has in research. As such, it is important for justifying and shaping a practical framework for governance. In developing this account we use a persuasive, central element of the democratic account discussed above: its location of enquiry and research within the grasp of society, rather than removed from it. However, as we have argued, a specifically democratic location misses something important about the nature of enquiry that transcends politics. Instead, a more fundamental account of the relationship between enquiry and human social life is required.

Enquiry and human life are intertwined and interdependent. To be human is to be curious, to ask questions about yourself, the world and your place in the world. This process of enquiry is undertaken individually, but is a social activity. It involves reflecting on what we value about ourselves in our relationships with others, and how we should collaboratively live our lives in ways that we think are good. By asking these questions we shape our own lives, and the lives of others, in particular waysboth in the process of asking such questions, and in the answers arrived at in consultation with others. As we shape our lives in these ways, the questions that we ask (about ourselves, our relationships with others and our place in the world) develop in an iterative process of enquiry. In this way, enquiry becomes embedded within the functioning of societies, with social life also arising from, and transformed by, enquiry. At the broad societal level, such transformations themselves create and re-create practices of enquiry. 
We can understand research as the institutionalisation of enquiry. Over time, these institutions (universities or other settings) develop systems of enquiry formalised around certain conventions about how enquiry should be conducted and what forms of knowledge are valid. In this respect, the activities undertaken within academic disciplines, research centres and publishing houses shape, in various ways and to varying extents, the conduct of particular 'academic' forms of enquiry, and our social world.

Using this account of the role of enquiry, and of research as a particular institutionalised form of enquiry, we can return to the question of society's stake in research. This account develops a claim of enquiry as being an important and indeed constitutive element of human flourishing: humans cannot flourish without enquiring. This claim is not simply about benefit or welfare maximisation. It comes from an Aristotelian tradition that understands human flourishing to involve not simply living with a certain levels of satisfaction and absence of harm, but engaging in particular forms of activity that are valuable irrespective of their outcome. ${ }^{34-36}$ Enquiry is, we suggest, one of these activities: a life may not go as well because of enquiry (ignorance may be bliss), but enquiry is necessary for flourishing ('the unexamined life is not worth living').

Further, society should be concerned with the flourishing of its members. Although the characterisation of the relationship between a society and its individual members varies, almost all accounts posit a concern by society for its members because society is viewed as more than the accidental, rough colocation of individuals. Most importantly, both our account of enquiry as a constitutive element of human flourishing and society's concern for its members are thin enough to include most political philosophies. So while overall accounts will vary in what counts as flourishing, and in society's obligations to its members with respect to flourishing, most will include some form of societal obligation that should reference activities associated with enquiry.

This fifth account shows something important about both the existence of society's stake in research and the nature of that stake: society has something to say about research because (1) research is an institutionalised form of enquiry, (2) enquiry is a constitutive element of human flourishing and (3) society should be concerned with the flourishing of its members.

\section{Responses to our account}

Before considering the ways in which our account can provide a general grounding for governance in social research, we consider some initial responses to this account of society's stake in social research.

One apparent problem with this account is that it relies on a distinction between social research and other forms of enquiry that meet our criteria for human flourishing. There are many forms and types of enquiry; why think that research is relevantly distinct from these other forms, particularly given that there will be consequences for governance in making such a distinction? Without the distinction between research and other forms of enquiry, any general claim for governance in social research will falter, unless one is going to also make the claim for the need to govern all aspects of human life in which institutionalised and non-institutionalised enquiry occurs.

On our account, research is a particular form of institutionalised enquiry that is distinct from other activities that take similar forms. Research has a status that other modes of enquiry, such as journalism, do not have, and the outputs of activities undertaken within these institutions have a distinct place in the public and political consciousness.
Moreover, the institutionalisation of enquiry within academic environments produces formalised arrangements between individuals who gather together with shared interests to develop research groupings of various forms. This system of formalised arrangements is characterised by historical trajectories and conventions about the objectives of research. Perhaps the clearest examples of this involve the redevelopment of methodologies for generating particular kinds of understanding about the world that render certain forms of knowledge valid or invalid.

To illustrate this point, consider the difference between the research methodology of autoethnography ${ }^{\text {iii }}$ and the social practice of autobiography. At first look, these activities look similar: they both offer personal narrative accounts of life experience. If there is no relevant distinction between the two activities, our general claim to ground governance in social research would either fail or extend to activities such as autobiography.

On reflection, however, they display important differences. If a person wrote her autobiography, she could tell whatever life story she wished, however she wanted. Publication might, of course, be unlikely, and readers lacking. In contrast, a male anthropologist might conduct participatory research and attend antenatal classes to understand how men engage with antenatal services. He might fulfil his study objectives effectively by writing an autoethnographic account of his experiences, so capturing the male perspective. In conducting autoethnography, the researcher would be held accountable by the disciplinary traditions rendering this form of enquiry valid for knowledge production. These traditions require a particular kind of confessional and reflexive style in study analysis and publication that justifies its review and acceptance by the researcher's peers.

These institutionalised traditions allow us to reject the claim of inconsistencies between the governance of social research and other forms of enquiry, which make research ethics governance in social research illegitimate. This is illustrated by developing the example introduced above. Suppose now that the man engaging in antenatal classes was a journalist who intended to publish his experiences in a newspaper, with the hope that men re-evaluate their preparental obligations. Again, this activity looks like autoethnography and ought to be classed as research. But, for this claim to work, this journalistic activity would need to be entirely consistent with the institution-specific traditions that validate certain kinds of knowledge production and dissemination, and which define research. Of course, if this were the case, then he would no longer be enquiring as a journalist, but as a researcher. And, on the basis of the account of the stake that society has in research outlined above, his activities ought to be governed as a piece of research.

The justification, then, for governing research stems from research's particular kind of involvement in our capacity to flourish as individuals within society. The exalted place of research in the institutional order of contemporary societies means that the understandings that emerge from research are taken seriously: they form policy and lead to changes in individuals' lives in ways that contribute to, or detract from, their flourishing as human beings in society. Let us be clear: it does not follow from this that research should be governed, and that

iii A reflexive account of a researcher's experiences of life in the field developed within the discipline of social anthropology. 
other institutionalised forms of enquiry should not be governed. Even if we recognise that research and, say, journalism differ, this does not imply that journalism (whether institutionalised within the media or otherwise) ought not to undergo ethical oversight and other governance mechanisms.

\section{Outlining a system of research ethics governance}

Where are we to this point? After presenting and developing the context in which research ethics governance has been criticised and exploring these kinds of criticisms, we turned our attention to the question of society's stake in research. We argued that, in order to develop a constructive account about the acceptability or otherwise of ethics governance, we need to be clearer about why society should have something to say about research under its auspices. The previous two sections considered a range of possible accounts of this stake, culminating in the last section our preferred account: understanding research, via the idea of enquiry, as importantly associated with human flourishing, and so as something about which society ought to be concerned. The other accounts helped to consider what research should take place but failed ultimately to provide a general grounding for the stake that society has in research. In this respect we are left with a set of relevant ethical considerations that are broadly captured as (1) the liberty of researchers and the right to research, (2) the accountability for the use of resources and (3) welfare, protection from harm and respecting research participants.

What remains is to explore how these ingredients lead to an account of the justifiability of governance and the form of that governance. Governance is, after all, only one way for society to exercise its stake in research.

Being clear about the question that needs addressing is an important step. We take it that the relevant question is about what (specific piece of) research ought to be conducted. This is certainly the question that we have been considering throughout this paper and it is the question that RECs are set up to answer. Other questions about research and the involvement of members of society in research relate to the discussions here but are beyond the paper's scope.

Two points follow from clarifying the relevant question of 'what specific research ought to be conducted?' First the question is one that can provoke reasonable disagreement. The researcher might assert his right to proceed. The funder may not see the potential social benefit of the research and so opt to support another 'more useful' project. An independent assessor (for example) may think that the research's risks outweigh its benefits and so object to it in its current form. In each case, the reasons given draw on an ethically relevant consideration. Notice that the possibility of reasonable disagreement does not imply anything about actual disagreement: some research projects may seem ethically unproblematic. It does, however, mean that we need to be careful about the process by which we assess the ethically relevant considerations.

Second, any decision in answer to this question should be given pre-emptively. Those who reject the idea that research ethics governance should be pre-emptive simply fail to see that there can be reasonable disagreement about whether the research should proceed. The arguments above illustrate why this view is unsustainable.

Given the question and the possibility of reasonable disagreement about what research should proceed, we require a method for making decisions that takes account of the ethically relevant considerations in order to reach a judgement. We suggest that a model of fair process, akin to the 'Accountability for Reasonableness' model, can be adopted here. ${ }^{37-41}$
Daniels and Sabin's original model of fair process in priority setting works in the context of reasonable disagreement about how the available resources ought to be divided. ${ }^{37}$ This model maintains that normative legitimacy and fairness are achieved by putting in place a just procedure. Normative legitimacy is secured through the process by which the decisions are made. Broadly, a fair procedure is one that would be agreed on by reasonable persons in the appropriate state of ignorance. The model involves four conditions that are necessary for a fair procedure. ${ }^{37}$ In the description below we have adapted (and slightly paraphrased) them to the research context. The brackets signify our insertions.

1. Publicity: Decisions regarding [research proposals] and their rationales must be made publicly accessible.

2. Relevance: The rationales for decisions should reasonably explain [the grounds for not permitting a piece of research]. Specifically, a rationale is reasonable if it appeals to evidence, reasons and principles that are accepted as relevant by fair-minded people who are disposed to finding mutually justifiable terms of cooperation.

3. Revision and appeal: There must be (1) mechanisms for challenging and resolving disputes about decisions, and (2) more broadly, scope to revise [decisions about the permissibility of research] in light of new evidence.

4. Regulative: The process [of ethical oversight] should be regulated (voluntarily or publicly) to ensure that conditions $1-3$ are met.

There is more to be said about the application of these conditions to research ethics governance than there is room for here. However, a number of comments are in order. First, each of the conditions helps to develop the connection between a system of governance and broader society, thus ensuring accountability. This accountability is important if the system is to be a fair one. The conditions represent appropriate checks and balances on the system that ensure that the rationales are relevant and provide a reasonable explanation. ${ }^{40}$

Second, as it does for Daniels and Sabin, the relevance condition plays a significant role in the justificatory story. What counts as relevant in a particular context will depend on what the properly disposed fair-minded person would find relevant. It may be objected that the idea of a fair-minded person is circular: a reasonable person is just someone who happens to reflect the dominant social paradigm, that is, what we happen to think is reasonable.

On our account, however, the reasonable person is defined in a non-circular way: this person recognises that the decision about a research project's permissibility is to be made in the context of reasonable disagreement. She genuinely attempts to consider the issues and judge the various reasons impartially. In contrast, someone is unreasonable if they think that all social research is a waste of time and money, as is someone who is oblivious to counterarguments to the research.

For our purposes, what is most important is that the account adequately supports the justification of a research ethics governance system. In the context of reasonable disagreement, and given that a decision needs to be made, this model establishes a fair process or system for deciding on the appropriateness of particular research projects. It does not overly restrict the kinds of considerations that are relevant, and is importantly characterised by an emphasis on the accountability for the reasonableness of decisions.

In concrete terms, this model provides the framework to justify a committee structure. It also has the normative resources to yield an account of committee make-up and standard 
operating procedures. Its appeal is in providing a context in which to balance out each of the considerations that are relevant to particular research proposals, without having to specify in advance either the form of this balancing or the ethically significant features of the context. So, in this framework, each of the considerations discussed in the second section above (which failed to provide a general grounding for governance but which retain ethical significance in the assessment of research) will very likely feature as considerations relevant to the decision-making. Thus the freedom to conduct research, the research's overall value to science and to society more broadly, and its participants' welfare are all pertinent considerations that can form the basis of reasonable decisions about research.

Most importantly, we take this model to provide a framework that is flexible in how it can handle different kinds of research raising different ethical issues. In the first section, we registered our concerns about the inappropriate application of the 'medical model' of governance to social research. Our model allows that a governance system may develop so that it can devolve responsibility and introduce mechanisms of proportionate review. The principles and processes implied by the accountability for reasonableness model can equally be applied to the system itself: changes to its specific structure and the form of its considerations can be justified through the proper consideration and articulation of relevant reasons. So, for example, if a certain form of research regularly raises one set of ethical concerns which are dealt with in the same way, the system 'learns' by establishing a pro forma or template that focuses the scrutiny in certain areas. The system still discriminates appropriately but at two stages: the primary stage of deciding whether a project qualifies for the pro forma and the secondary stage of focused scrutiny. Such results of system learning would need to be adopted and approved in the appropriate way and should be audited at regular intervals.

The system of governance may also be adapted to particular challenges that the research poses. For example, a research opportunity may present itself in a remote location with no time for prospective REC review and approval. The REC might deputise individuals 'on the ground' with prior research expertise and familiarity with the local context to represent their interests (the interests of the system). Deputies could liaise with the research team and report back to the committee on the progress of the research. Again, this form of system devolution is one that could be considered as a part of the accountability for reasonableness model: if the relevant reasons are considered together, the system itself can be adjusted. In this example, there would again be questions about audit, as well as questions about the deputies' accountability to the committee.

\section{CONCLUDING REMARKS}

We have defended a general claim for a system of research ethics governance in social research. This general claim, and the way in which we have developed it into a more specific framework for governance, is mindful of the practical concerns that have been raised about the governance mechanisms in place for social research. Together, the arguments for this claim provide a constructive and general response to those who have presented piecemeal arguments against research ethics governance in social research.

We have argued that society has a stake in social research because of its link to enquiry. Enquiry, we suggested, is a constitutive element of human flourishing, and society ought to be concerned with the flourishing of its members. Social research is one form of enquiry, institutionalised in particular ways and according to certain trajectories of tradition and social convention. So society has a stake in social research. Identifying this stake does not settle questions about the extent and nature of the involvement of society in research, but the investigations of this stake identify a number of ethical considerations that are relevant for understanding this involvement.

Importantly, individual members of society can reasonably disagree about what specific research should be conducted within a society. This reasonable disagreement justifies implementing a 'fair process' model of governance that will enable these decisions to be made ethically. The 'accountability for reasonableness' model outlined above helps structure the overall way in which research ethics governance might be organised. This model is flexible and reflexive, and as such is well suited to the methodological and practical concerns of social researchers.

Acknowledgements MS is grateful for the support of the Oxford NIHR Biomedical Research Centre. We would like to thank audiences at the 'Research Ethics Committees: Help or Hindrance?' Conference, University College London, the 'Research Ethics in Europe - what is done and how it could be done better? Workshop at Keele University, the Mt Sinai Consortium on Bioethics, and the St Cross College Ethics Seminar, University of Oxford.

Contributors MS and MD drafted the initial version. KS led on revisions and finalising the manuscript.

Competing interests None declared.

Provenance and peer review Not commissioned; externally peer reviewed.

(c) Article author(s) (or their employer(s) unless otherwise stated in the text of the article) 2018. All rights reserved. No commercial use is permitted unless otherwise expressly granted.

\section{REFERENCES}

1 US-DHHS. The common rule. Code of federal regulations Title 45 Public welfare department of health and human services part 46 protection of human subjects, 2009

2 CAN. Canadian Institutes of Health Research, Natural Sciences and Engineering Research Council of Canada, and Social Sciences and Humanities Research Council of Canada. Tri-council policy statement: ethical conduct for research involving humans, 2014.

3 AUS. National statement on ethical conduct in human research 2007 (Updated May 2015). Canberra: The National Health and Medical Research Council, the Australian Research Council and the Australian Vice-Chancellors' Committee. Commonwealth of Australia, 2015. www.nhmrc.gov.au/guidelines/publications/e72 (accessed 18 Apr 2017).

4 SRA. Ethical guidelines, social research association. 2003 http://the-sra.org.uk/wpcontent/uploads/ethics03.pdf (accessed 18 Apr 2017).

5 ASA. Ethical Guidelines for good research practice, Association of Socia Anthropologists of the UK and the Commonwealth (ASA). 2011 http://www.theasa. org/downloads/ASA\%20ethics\%20guidelines\%202011.pdf (accessed 18 Apr 2017).

6 ESRC. Framework for research ethics, economic and social research council. 2015 http://www.esrc.ac.uk/files/funding/guidance-for-applicants/esrc-framework-forresearch-ethics-2015/ (accessed 18 Apr 2017).

7 Hammersley M, Traianou A. Moralism and research ethics: a Machiavellian perspective. Int J Soc Res Method 2011;14(5):379-90.

8 Hedgecoe A, Carvalho F, Lobmayer $\mathrm{P}$, et al. Research ethics committees in Europe: implementing the directive, respecting diversity. J Med Ethics 2006;32(8):483-6.

9 Hammersley M. Against the ethicists: on the evils of ethical regulation. Int J Soc Res Methodol 2009:12(3):211-25.

10 Dixon-Woods M, Angell E, Ashcroft RE, et al. Written work: the social functions of Research Ethics Committee letters. Soc Sci Med 2007;65(4):792-802.

11 Dingwall R. The ethical case against ethical regulation in humanities and social science research. Twenty-First Century Society 2008;3(1):1-12.

12 Erdos D. Systematically handicapped? Social research in the data protection framework. Information \& Communications Technology Law 2011;20(2):83-101.

13 Hammersley M, Traianou A. Foucault and research ethics. Qualitative Inquiry 2014:20(3):227-38.

14 Wald DS. Bureaucracy of ethics applications. BMJ 2004;329(7460):282-4.

15 Dingwall R. An exercise in fatuity: research governance and the emasculation of HSR. J Health Serv Res Policy 2006;11(4):193-4.

16 Roberts I, Prieto-Merino D, Shakur $\mathrm{H}$, et al. Effect of consent rituals on mortality in emergency care research. Lancet 2011:377(9771):1071-2.

17 Derbyshire S. The Ethical Dilemma of Ethical Committees. Sociology Compass 2008;2(5):1506-22. 
18 Dyck M, Allen G. Is mandatory research ethics reviewing ethical? J Med Ethics 2013;39(8):517-20.

19 Johnsson L, Eriksson S, Helgesson G, et al. Making researchers moral: Why trustworthiness requires more than ethics guidelines and review. Research Ethics 2014;10(1):29-46.

20 Dingwall R. "Turn off the oxygen ..." . Law Soc Rev 2007;41(4):787-96.

21 Dyer S, Demeritt $D$. Un-ethical review? Why it is wrong to apply the medical mode of research governance to human geography. Progress in Human Geography 2009;33 (1):46-64.

22 Librett M, Perrone D. Apples and oranges: ethnography and the IRB. Qualitative Research 2010;10(6):729-47.

23 Alderson P, Morrow V. Multidisciplinary research ethics review: is it feasible? Int I Soc Res Methodol 2006;9(5):405-17.

24 Richardson S, McMullan M. Research ethics in the UK: what can sociology learn from health? Sociology 2007:41(6):1115-32.

25 Reed K. Bureaucracy and beyond: the impact of ethics and governance procedures on health research in the social sciences. Sociological Research Online 2007(5);12:18.

26 Hamburger P. The new censorship: Institutional Review Boards. The Supreme Court Review 2004, 2005:271-354.

27 Foer F. Closing of the presidential mind. The New Republic 2004;231:17-21.

28 Mooney C. The Republican war on science. New York: Basic Books, 2005.

29 GAfREC. Governance arrangements for research ethics committees: a harmonised edition: Prepared by the UK Health Departments: Department of Health Research and Development Directorate (England) National Institute for Social Care and Health Research (NISCHR) (Wales) Chief Scientist Office Scotland) R\&D Division, Public
Health Agency, 2011. https://www.gov.uk/government/uploads/system/uploads/ attachment_data/file/213753/dh_133993.pdf (accessed 18 Apr 2017).

30 Erikson KT. A comment on disguised observation in sociology*. Social Problems 1967:14(4):366-73.

31 Warwick D. Types of harm in social research. Beauchamp TL, ed. Ethical issues in social science research. . Baltimore: Johns Hopkins University Press, 1982.

32 Oakes JM. Risks and Wrongs in Social Science Research. Evaluation Review 2002;26(5):443-79.

33 Brown MB, Guston DH. Science, democracy, and the right to research. Sci Eng Ethics 2009;15(3):351-66.

34 Rorty AO. Essays on Aristotle's ethics. Berkeley: University of California Press, 1981.

35 MacIntyre A. After virtue. London: Duckworth Press, 1981.

36 Broadie SW. Ethics with Aristotle. Oxford University Press: Oxford, 1991.

37 Daniels N, Sabin J. Limits to health care: fair procedures, democratic deliberation, and the legitimacy problem for insurers. Philos Public Aff 1997;26(4):303-50.

38 Daniels N. Accountability for reasonableness. BMJ 2000;321(7272):1300-1.

39 Edwards SJ, Ashcroft R, Kirchin S. Research ethics committees: differences and moral judgement. Bioethics 2004;18(5):408-27.

40 Sheehan M. Should research ethics committees meet in public? J Med Ethics 2008;34(8):631-5.

41 McGuinness $S$. Research ethics committees: the role of ethics in a regulatory authority. J Med Ethics 2008;34(8):695-700.

42 Buchanan A, Keohane RO. The Legitimacy of global governance institutions. Ethics Int Aff 2006;20(4):405-37 